\title{
Permeability Acquiring and Application for Coal Reservoir
}

\author{
Wen-guang ZHAO* \\ Research Institute of Petroleum Exploration \& \\ Development, Petrochina \\ Beijing, 86100083, China \\ e-mail: zhaowenguang@petrochina.com.cn

\section{Chun-lei LI} \\ Research Institute of Petroleum Exploration \& \\ Development, Petrochina \\ Beijing, 86100083, China \\ e-mail: lichunlei@petrochina.com.cn
}

\author{
$\mathrm{Na}$ LI \\ Shengli Oilfield Company, Sinopec, Laboratory, \\ Dongying, 86257000, China \\ e-mail: lnlb2000@126.com
}

\begin{abstract}
Permeability is important in evaluating coal reservoir, and the acquiring methods are various. In this paper, four main methods, i.e., drill stem test (DST), diagnostic fracture injection test (DFIT), production data analysis, and simulation were introduced. Though the hypothesis condition and application limitation are different, generally speaking, the first three methods should be adopted in the single-phase flow condition, and the fourth should be used in two-phase flow condition. Since an accurate permeability is difficult to acquire, the uncertainty range should be presented when analyzing permeability, and the determining method was also discussed.
\end{abstract}

Keywords- Permeability; Coal reservoir; Drill stem test; Diagnostic fracture injection test; Production data analysis, Simulation.

\section{INTRODUCTION}

Permeability is the most critical parameter for economic viability of a gas-containing coal. It is also the most difficult parameter to evaluate accurately. Generally speaking, the acquiring methods could be divided into two types in field, i.e., testing and calculating methods. For the testing method, drill stem test (DST) [1] and diagnostic fracture injection test (DFIT) [2] were used widely. For the calculating method, production data analysis[3], and simulation were recommended. However, more attention should be paid to permeability selecting and using, since the hypothesis conditions and application limitations are different for each other. In this paper, several common testing and calculating methods of permeability for coal reservoir were presented, and the advantage and disadvantage were also discussed. Finally, the application methods of permeability to coal reservoir were introduced.

\section{TESTING Methods OF PERMEABILITY}

\section{A. DST Method}

DST is employed in coal reservoir to determine permeability. During test, target coal seam is isolated with inflatable packers. There are four periods in this test, namely pre-flow, initial shut-in, main flow, and final shut-in period. The first flow period is to clean up the well, while the initial shut-in allows pressure in the tool to approach reservoir pressure. The main flow period is performed to determine the formation flow characteristics. The final shut-in allows the pressure in the reservoir to build-up to initial conditions. GRI recommends an initial flow period of 5 to 30 minutes, an initial shut-in duration of 4 to 8 times the initial flow period, a main flow period of 3 to 8 hours, and a final shut-in period at least 1.5 times the length of the final flow period [1]. The pressure should be continuously monitored using downhole pressure gauges. The permeability is calculated from the pressure build-up of the final shut-in period.

\section{B. DFIT Method}

DFIT incorporates the G-function derivative analysis and identifies four distinct signatures seen in coal well, namely normal leak-off, pressure dependent leak-off, fracture-tip extension and fracture height recession.

Normal leak-off, which occurs from a constant fracture area in a homogeneous formation, was reported to occur in approximately $1 \%$ of all coal well DFITs. Pressure dependent leak-off is the predominant response seen in coal well DFITs, occurring in $75 \%$ of all tests studies. This signature is seen in tests with multiple fractures which depends on time interval analyzed. Analysis of early-time data will yield a permeability representative of dilated cleats, while analysis of late-time data, after fracture closure, will result in permeability closer to that prevailing during depletion. Consequently, care should be taken to assure that late-time data are selected for analysis. Fracture-tip extension, occurring in $10 \%$ of coal tested, is seen in tests of low leakoff, tight rock. Fracture height recession is seen in only $14 \%$ of coal well DFITs and occurs when in-situ stress is sufficient to heal the top and/or bottom of fracture during shut-in[2].

DFIT is a small-volume, cost-effective, and shortduration test that has been used successfully in coal reservoir. Meanwhile, this method has several limitations. Interpretation of before-closure data depends on rock 
properties, which is qualitative, and the radius of investigation is quite small. In addition, after-closure analysis requires pseudoradial flow to develop, which may not occur in a reasonable time frame for low permeability coals.

\section{CAlculating Methods of PeRmeability}

\section{A. Production Data Analysis}

Permeability can be calculated by combining productivity index with Darcy's law from the production data of any well producing in coalbed methane field, of which Joshi's method was predominantly used [3]. The formula of Joshi method is as follow:

$$
J_{h}=\frac{0.00708 h k_{h}}{\mu \beta\left[\operatorname{Ln}\left[\frac{a+\sqrt{a^{2}-\left(\frac{L}{2}\right)^{2}}}{\left(\frac{L}{2}\right)}\right)+\frac{k_{h} h}{k_{v} L} \operatorname{Ln}\left(\frac{h}{2 r_{w}}\right)\right]}
$$

Where $\quad a=\left(\frac{L}{2}\right)\left[0.5+{\sqrt{0.5+\left(\frac{2 r_{e h}}{L}\right)^{4}}}^{0.5}\right.$

Where: $\mathrm{J}_{\mathrm{h}}$ is productivity index, $\mathrm{STB} /$ day/psi; $\mathrm{h}$ is reservoir thickness, $\mathrm{ft} ; \mathrm{k}_{\mathrm{h}}$ is horizontal permeability, $\mathrm{mD} . \mu$ is water viscosity, $\mathrm{cp} ; \beta$ is formation volume factor; $\mathrm{L}$ is length of the horizontal well, $\mathrm{ft} ; \mathrm{k}_{\mathrm{v}}$ is vertical permeability, $\mathrm{mD} ; \mathrm{r}_{\mathrm{w}}$ is wellbore radius, $\mathrm{ft}$; $\mathrm{a}$ is half the major axis of the drainage ellipse, $\mathrm{ft} ; \mathrm{r}_{\mathrm{eh}}$ is drainage radius, $\mathrm{ft}$.

By contrast to DST and DFIT, this method is only based on water production data and several reservoir parameters, and hence a better economic viability. The disadvantage is that some assumptions inherent in this method are not identical with real reservoir condition, such as single phase flow; flow rate is controlled by article lift mechanism; skin is assured to be constant; reservoir pressure is constant and equal to the static water pressure at the seam depth; and radial flow.

\section{B. Simulation}

Permeability is a necessary parameter for reservoirsimulation history matching of coalbed methane, and the data attained by DST, DFIT, production data analysis, or other methods must be loaded into the model. If permeability of this well is available, it could be used directly as the initial value. If not, value of the same seam from adjacent well or calculated by the relationship of permeability with depth in this area can be used. Since same history matching results can be attained by various parameter settings, the best simulation case should be the one with all the used data, including permeability, gas content, Langmuir parameters, within their uncertainty range, which will be introduced later. In the example given in Fig. 1, the final simulated permeability (red dot) lies in the high and low bands.

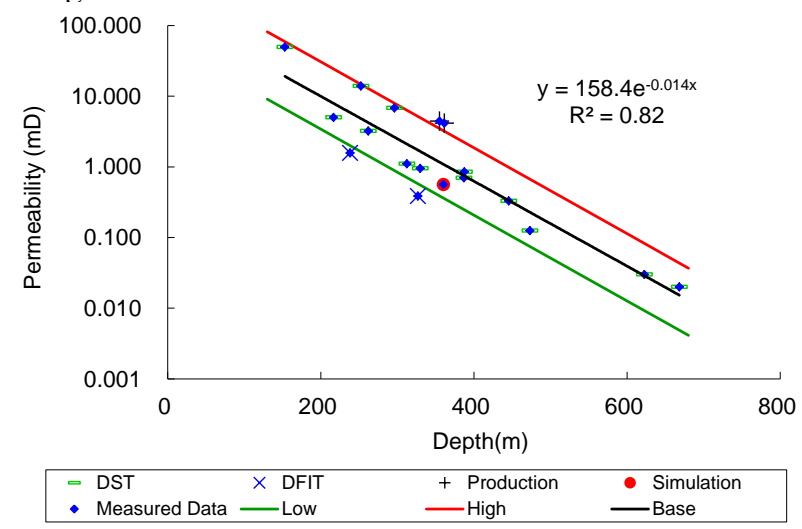

Figure 1. Measure permeability versus depth

The permeability attained by simulation refers to permeability data derived from other methods, and hence with a higher reliability, meanwhile this result can also be used to verify the accuracy of data attained earlier. Because a number of parameters are used in history matching, and each parameter has it's own uncertainty, the accuracy of attained permeability depends on the cognition on reservoir and the skill of engineer.

\section{APPLICATION OF PERMEABILITY}

Though permeability of coal reservoir is influenced by many factors, including depth, rank, cleat aperture size [4], the most predictable relationship with permeability is depth. Almost without exception, the deeper you go, the less permeable the coal reservoir will be. However, at any particular depth there can still be considerable variability in permeability. Taking Fig. 1 as an example, at the depths of $360 \mathrm{~m}$, the permeability varies from less 1 to more than 4 $\mathrm{mD}$. In other words, significant uncertainty exists, which may be related to coal heterogeneity and difficulty in obtaining reliable permeability measurement.

The first step in quantifying this uncertainty is to calculate the residuals between the fitted line and each data measurement. Table 1 shows how this is done for the dataset shown in Fig. 1, a set of permeability measurements and associated trend. Note that since the permeability versus depth trend is exponential, the residuals are calculated as the difference between the natural $\log$ of the calculated and measured permeabilities. To capture the uncertainty at a specific location, high and low bands are drawn to enclose the scatter of data. As shown in Fig. 1, the bands are usually drawn by analyzing the residual distribution and choosing the 10th and 90th percentile values of the distributions, which guaranteed that some data points would, in fact, lie outside the high and low bands.

If we need the permeability at a depth, we can get this value and its uncertainty range easily from the plot of permeability versus depth of this area. 
TABLE I. CALCULATION OF RESIDUALS FOR EXAMPLE DATASET OF FIG.1

\begin{tabular}{ccccc}
\hline $\begin{array}{c}\text { Dept } \\
\mathrm{h} \\
(\mathrm{m})\end{array}$ & $\begin{array}{c}\text { Measured } \\
\text { Permeability } \\
(\mathrm{mD})\end{array}$ & $\begin{array}{c}\text { Calculated } \\
\text { Permeability } \\
(\mathrm{mD})\end{array}$ & $\begin{array}{c}\text { Resid } \\
\text { ual }\end{array}$ & Source \\
\hline 153.0 & 49.56 & 18.60 & 0.98 & DST \\
216.7 & 5.00 & 7.62 & -0.42 & DST \\
252.3 & 13.90 & 4.63 & 1.10 & DST \\
262.0 & 3.21 & 4.04 & -0.23 & DST \\
296.3 & 6.80 & 2.50 & 1.00 & DST \\
312.5 & 1.10 & 1.99 & -0.59 & DST \\
329.7 & 0.95 & 1.57 & -0.50 & DST \\
386.9 & 0.70 & 0.70 & -0.01 & DST \\
387.5 & 0.85 & 0.70 & 0.20 & DST \\
445.5 & 0.33 & 0.31 & 0.06 & DST \\
473.2 & 0.13 & 0.21 & -0.52 & DST \\
622.5 & 0.03 & 0.03 & 0.14 & DST \\
668.2 & 0.02 & 0.01 & 0.38 & DST \\
238.1 & 1.57 & 5.65 & -1.28 & DFIT \\
326.8 & 0.39 & 1.63 & -1.44 & DFIT \\
355.0 & 4.43 & 1.10 & 1.39 & Productio \\
361.4 & 4.14 & 1.01 & 1.41 & Productio \\
& & & & n
\end{tabular}

\section{CONCLUSIONS}

Different methods could be used to acquire permeability in different stages of coalbed methane development. DST, DFIT and production data analysis methods should be adopted in the single-phase flow condition, or it is difficult to interpret due to complications from relative permeability effects. Simulation method can be used in two-phase flow condition, and it is one of the aims to get permeability, meanwhile the value acquired by this method can also be used to verify the accuracy of data attained by other methods.

Due to coal heterogeneity and other reasons, accurate evaluating of permeability is difficult. So not only a special value but also the uncertainty range at one depth should be determined when analyzing permeability, in this study, the 10th and 90th percentile values of the distributions are adopted.

\section{REFERENCES}

[1] M. Ramurthy, D.M. Marjerisson, and A.B. Daves: SPE 75701(2002)

[2] S.D. Joshi: Journal of Petroleum Technology, Vol. 40(1988), P.729739

[3] T.A. Moore: International Journal of Coal Geology, Vol. 101(2012), P.36-81

[4] A. P. Jared, M. Saiket, N. Siddharta, in: International Petroleum Technology Conference held in Beijing, China, 26-28 March 2013 